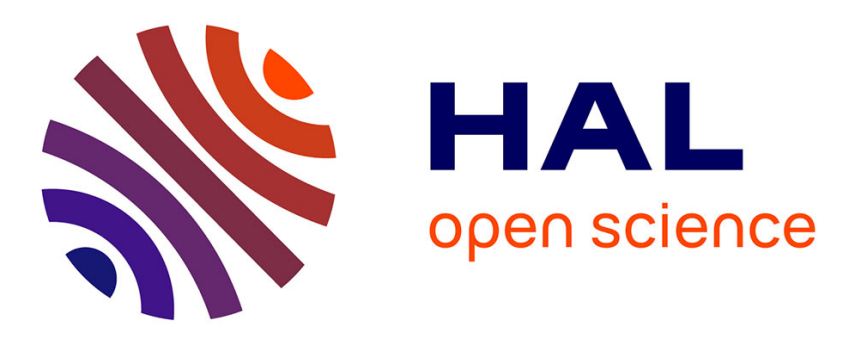

\title{
SDI, NATO, and the Social Composition Function
}

Ghislain Dutheil de La Rochère, Jean-Michel Josselin, Yvon Rocaboy

\section{To cite this version:}

Ghislain Dutheil de La Rochère, Jean-Michel Josselin, Yvon Rocaboy. SDI, NATO, and the Social Composition Function. Defence and Peace Economics, 2013, 25 (2), pp.85-95. 10.1080/10242694.2013.774772 . halshs-00875580

\section{HAL Id: halshs-00875580 \\ https://shs.hal.science/halshs-00875580}

Submitted on 12 Oct 2014

HAL is a multi-disciplinary open access archive for the deposit and dissemination of scientific research documents, whether they are published or not. The documents may come from teaching and research institutions in France or abroad, or from public or private research centers.
L'archive ouverte pluridisciplinaire HAL, est destinée au dépôt et à la diffusion de documents scientifiques de niveau recherche, publiés ou non, émanant des établissements d'enseignement et de recherche français ou étrangers, des laboratoires publics ou privés. 


\title{
SDI, NATO, and the social composition function FINAL REVISION
}

\author{
Ghislain Dutheil de la Rochère*, Jean-Michel Josselin§ and Yvon Rocaboy§ \\ Affiliations: * Ecole Spéciale Militaire de Saint-Cyr Coëtquidan, France \\ $\S \quad$ University of Rennes I, France, Centre National de la \\ Recherche Scientifique (CREM UMR 6211), France. \\ Correspondent: Jean-Michel Josselin \\ Faculté des sciences économiques \\ 7, place Hoche CS 86514 \\ F-35065 Rennes cedex, FRANCE \\ jean-michel.josselin@univ-rennes1.fr
}

\begin{abstract}
The Strategic Defense Initiative (SDI) intends to renew the leadership of the USA on the western alliance. The initiative takes place in a period when a summation technology prevails for the aggregation of contributions of NATO allies. We investigate whether SDI induces a shift in Hirshleifer's social composition function. Panel data tests over the period 1970-1990 do not confirm any break towards a bestshot aggregator. SDI does not alter the core of deterrence. It is indeed a public good at the US level but not at the NATO level, where it is one of the joint products of the alliance. We also investigate the lessons to be drawn for the current debates on ballistic defense.
\end{abstract}

\section{JEL classification: D74, H56, H87.}

Key-words: International public goods, social composition function, international organizations, alliances, best-shot, NATO.

Earlier versions of this paper have been presented at the 2012 world congress of the Public Choice Societies, Miami and at the GSHBC seminar of the University of Jena, 2011. We thank all participants to those events who gave us comments, especially Andreas Freytag and Sebastian von Engelhardt. We also thank an anonymous referee for his/her suggested revisions. The usual caveat applies. 


\section{SDI, NATO, and the social composition function}

\section{Introduction}

According to Hirshleifer (1983), the social composition function of an alliance can be summation (Samuelson 1954) but also best-shot or weakest link (Cornes 1993; Cornes and Hartley 2007). Collective action significantly depends on the prevailing technology of aggregation of allies' contributions (Sandler 2006). The shared defense of NATO is a fine example of the evolution of the social composition function of an alliance. The nuclear policy and technology of the USA in the 1950s prompt a bestshot that prevails until 1970, when the alliance moves to a summation technology from 1971 to 1990 , then to another summation period, characterized by increased strategic behaviors (Sandler and Forbes 1980; Gadea et al. 2004; O’Neal and Elrod 1989; Khanna and Sandler 1996; Dutheil et al. 2011). At the midst of the first summation period, President Reagan initiates the Strategic Defense Initiative (SDI). The so-called Star War project will never be really completed but from its inception it contributes to a dramatic increase in military space expenditures (Zervos 2004). Admittedly, President Reagan does not properly reach the aim of an effective SDI, in budgetary and military terms (Freedman 2003). SDI nevertheless remains a prominent feature of Mr. Reagan's first mandate. The aim is to develop a National Missile Defense (NMD) system, an innovative laser-based concept designed to protect the United States from long range nuclear missile attacks. Political will is definitely at the origin of SDI. It is a means to a renewed leadership of the USA. However, being a national rather than a theater missile defense system, this system is controversial (O’Hanlon 1999). 
The controversy is ongoing. The new strategic concept of NATO emanating from the Lisbon Summit in November 2010 cites as a new threat the proliferation of ballistic missiles and nuclear weapons. In order to face it, NATO leaders have decided to develop missile defense capacities. The first step has been to provide protection to NATO deployed forces, with theatre missile defense. The next step consists in protecting the civil populations of all NATO allies, with territorial missile defense. In June 2011, NATO Defense Ministers approved the NATO Ballistic Missile Defense Action Plan. This important strategic move will concern all the allies but the first contributor for the technologies involved remains the USA. Even if the time horizon for the plan is a decade, it can have an impact on the present behavior of the allies and it could drive the alliance towards a period of best-shot technology for the aggregation of individual contributions to NATO. In this renewed context, understanding what happened during the Star War period can illuminate the ongoing strategic shifts towards territorial missile defense. In particular, it can provide lessons about the likely evolution of aggregation technologies in the alliance.

To our knowledge, the few existing economic studies of SDI mainly focus either on the USA-USSR arms race (Zervos 2004) or on the deterrence-defense tradeoff in a game-theoretic framework (Brams and Kilgour 1988). Insightful though these are, those studies do not take into account two dimensions of the NMD system designed by the Reagan administration, which we would like to study here. First, we investigate the social composition function of the alliance. NMD is evidently a national program, but the national policy of the former best-shot of the western alliance might be expected to extend its impact beyond strictly national interests. Now, SDI is conceived during a period when NATO works under a summation aggregation technology, which leads us to our second point. In budgetary and strategic 
terms, SDI is an endeavor of tremendous policy consequences: deterrence has indeed been the key to the initial strategy of NATO. Can it be replaced with defense provided by the US NMD? Can we find empirical evidence that SDI provided a best-shot during the nineteen-eighties? Instead of adopting a long term perspective for the identification of social composition functions (Gadea et al. 2004; Dutheil et al. 2011), we focus our statistical analysis on the period 1970-1990 in order to try to capture and identify a possible breakpoint in aggregation technologies for the NATO alliance during the SDI period. We thus follow the track of Conybeare et al. (1994) who investigate and propose ways of distinguishing best-shot, weakest-link and summation aggregation technologies in military alliances, with an empirical focus on World War One and Cold War alliances. We will show that our results corroborate their own analysis of NATO over the period 1961-1987, though they are obtained through a different empirical strategy.

The article is organized as follows. Section 2 describes the way in which SDI is both a technological innovation and a political will that can alter the social composition function of the alliance. Section 3 presents the econometric results testing the possibility for the USA to become a best-shot in NATO during the nineteen-eighties. Section 4 provides a discussion of those empirical results.

\section{2. "The Cold War is over": the political economy of Star War}

The above quotation is from President Reagan leaving office in January 1989 after two mandates. In the early 1980s, US-Soviet relations enter a phase of intense friction, potentially as dangerous as the 1962 Cuban missile crisis. The magnitude of the perceived threat is probably amplified by the US presidential campaign of 1980 . Nevertheless, when the then elected President Reagan launches the Strategic Defense 
Initiative with his speech of March 23, 1983, it spurs or revives the space arms race between the two superpowers of the time. Econometric evidence (Zervos 2004) reinforces the argument that SDI contributes to the bankruptcy of the Soviet Union. At the time of its launching however, heated arguments fuel a debate full of technical and strategic controversies. Greenberg (2000) mentions how SDI can be conceived as a bargaining chip for arms control negotiations. It can also be interpreted as a way to undermine the 1972 Anti-Ballistic Missile Treaty, providing a way to modify it rather than withdrawing from it (O'Hanlon 1999), thereby minimizing the diplomatic consequences of a rather bold initiative.

Interpreted in the social composition function framework of Hirshleifer, SDI is a defense innovation supported by the political power in an attempt to strengthen the US position against the Soviet threat. A likely consequence is that the USA may again become a best-shot within NATO. Now, if we adopt a long run perspective, the inception of SDI approximately takes place in the middle of a period of summation technology for the NATO alliance. 1970-1990 is indeed characterized by the flexible escalation doctrine by which primary fronts involve non-nuclear engagements only, nuclear weapons being kept within second stage interdiction strikes. The technology of aggregation of technologies in the western alliance has thus moved from a bestshot played by the USA from 1955 to 1970 , to a summation composition function that gives a renewed weight to conventional forces. Behind this change in aggregation technology lays a new strategic doctrine put forward by NATO directive MC14/3 of January 16, 1968 whereby "The conventional forces of the Alliance, land, sea and air, many of which are organically supported by tactical nuclear weapons, are a further essential component of the deterrent" (MC14/3, 25c; see also MC14/3, A8). This new strategic concept is to be implemented through measures described in NATO directive 
MC48/3 of December 8, 1969. The USA does follow the strategic line proponing "The requirement for adequate conventional forces and for improving capabilities for non-nuclear operations while maintaining NATO's nuclear capability. This should include achieving optimum dual capability, especially in air forces, and the flexibility to employ these forces in non-nuclear operations" (MC 48/3, 5b). Concurrently, the American political scene progressively develops a rhetoric pushing forward the imminent Soviet domination, culminating with Ronald Reagan's election. SDI can be seen as an attempt to go beyond the current state of strategic military doctrine of the time. That political will would involve a change in the aggregation technology of the western alliance.

It is true that SDI is never properly realized as such, if only because the timescale for implementation would be decades rather than years. In the meantime, arms control progressively appears to be a more plausible means of escaping from mutual assured destruction (as evidenced for instance by the December 1987 treaty aiming at eliminating intermediate nuclear forces). Nevertheless, as a political initiative, the simple announcement of SDI breeds such hostility on the Soviet side that it reinforces its credibility, probably more than is deserved (Freedman 2003). Furthermore, budgets point at a "best-shot" effort by the USA. Since the announcement of SDI in 1983, the USA has spent $\$ 3.5$ billion a year on missile defense programs (O’Hanlon 1999). The rise in space military expenditures matches that of the early 1960s during the space race between "Apollo and Sputnik". Furthermore, Zervos (2004) identifies 1986 as the date when the US space military expenditures surpass the Soviet ones for the first time in history, as a consequence of a trend rooted back in the mid-1970s. The ensuing candidacy for best-shot is exemplified by Sandler (2006): the "Star War" best-shooter has the capability to destroy enough missiles from the first strike of the enemy to 
deter it from attacking. At the scale of the alliance, only one such system is required. The defense missile system can at first glance be viewed as a best-shot public good. There remains to check whether it is the case or not.

\section{Econometric analysis}

The theoretical setting behind our empirical investigations is that of a joint product model of alliance. A pure public good best-shot model would imply zero contributions by non best-shot allies and obviously would not be realistic in our case. The joint product model is thus a rather more adequate framework. In a joint product setting, Nash equilibrium conditions have been provided by Sandler (1977) in the summation case and by Conybeare et al. (1994) in the best-shot case. We use here a simple model to describe both cases. The alliance consists of countries $i=1, \cdots, I$. Allies have initial endowments $y_{i}$ (e.g. annual GDP) with numéraire $x_{i}$ expressing private consumption as well as the provision of non-military national public goods. Defense activity $q_{i}$ with unit price $p$ involves a contribution to the alliance-wide deterrence $G$ and an ally-specific local public good. The utility function is

$$
u_{i}=u_{i}\left(x_{i}, q_{i}, G\left(q_{1}, \ldots, q_{i}, \ldots, q_{I}\right)\right)
$$

The Nash program of a given ally $i$ is (Cornes and Sandler 1984)

$$
\begin{array}{cl}
\max _{x_{i}, q_{i}} & u_{i}=u_{i}\left(x_{i}, q_{i}, G\left(q_{1}, \ldots, q_{i}, \ldots, q_{I}\right)\right) \\
& \text { subject to } x_{i}+p q_{i}=y_{i}
\end{array}
$$

Following Dutheil et al. (2011), in the case of a summation aggregation technology, the reaction function of ally $i$ is

$$
\text { (1) } \quad q_{i}=f_{i}\left(G_{-i}, y_{i}, p\right)
$$


With $G_{-i}$ the sum of the defense expenditures of allies other than ally $i$. In the bestshot case, the reaction function of non best-shot country $i$ is

$$
\text { (2) } \quad q_{i}=f_{i}\left(G_{\max }, y_{i}, p\right)
$$

With $G_{\max }$ the defense expenditure of the best-shot ally; the latter has the reaction function $q_{\max }=f_{\max }\left(y_{\max }, p\right)$. Equipped with those testable forms, we now move on to the empirical analysis per se.

The panel goes over the period 1970-1990 for 14 NATO allies (Belgium, Canada, Denmark, France, Germany, Greece, Italy, Luxemburg, the Netherlands, Norway, Portugal, Turkey, the UK, and the USA). Data is obtained from NATO 2009 sources for national defense expenditures (denoted by $D E F_{i}$ for ally $i$ ) and IMF 2008 for GDP (denoted by $G D P_{i}$ ). Units are million USD and the logarithm of variables is used in the regressions on this balanced panel data set. Under a summation technology, considering a given ally $i$, the other allies' cumulated defense efforts are denoted by $S U M_{i}=\sum_{j \neq i} D E F_{j}$. Under a best-shot technology, $B S_{i}=\max _{j \neq i} D E F_{j}$ with $B S_{\text {Best-shot }}=0$.

In the first stage we use OLS with the Panel Corrected Standard Errors (PCSE) method (Beck and Katz 1995) with fixed effects and lagged variables. Two models are tested, each of them characterized by an aggregation technology assumed to be constant over the whole period 1970-1990:

$$
D E F_{i, t}=\alpha_{1, i}+\beta_{1} G D P_{i, t}+\gamma_{1} S U M_{i, t-1}+\varepsilon_{i, t}
$$

(4) $D E F_{i, t}=\alpha_{2, i}+\beta_{2} G D P_{i, t}+\gamma_{2} B S_{i, t-1}+\varepsilon_{i, t}$

Equation 3 is the reaction function of ally $i$ within a summation technology (equation 1) while equation 4 corresponds to the best-shot case (equation 2). Table 1 provides the estimations of the two equations. Coefficients for GDP are significant at the $1 \%$ 
level. However, none of the two aggregation technologies have significant coefficients. We thus hypothesize that a break may occur during the period, with a shift from one social composition function to another or a change in the behavior of the allies within a given technology of aggregation.

(Table 1 about here)

The empirical strategy is then to introduce unknown breakpoints $d_{k}$ within the period. We define them in the following way:

$$
\text { (5) } \quad T E C H 1_{i, t-1}=d_{k} \times T E C H_{i, t-1}
$$

The aggregation technology is represented by variable $T E C H$, which is such that $T E C H=S U M$ or $B S$. The social composition function can be either summation or best-shot. Dummy variable $d_{k}$ takes value 1 from 1970 until year $k$ and value 0 afterwards. Until date $k, T E C H 1=S U M 1$ or $B S 1$ : during the first period, summation or best-shot can prevail. Afterwards, TECH2 $=S U M 2$ or $B S 2$ : there may or may not be a shift in the aggregation technology.

Still using the PCSE method, we test all possible combinations of breakpoints $d_{k}$ from 1970 to 1990 and of aggregation technologies (for instance BS1 then SUM2 or SUM1 then SUM2):

(6) $D E F_{i, t}=\alpha_{i}+\beta G D P_{i, t}+\delta_{1} T E C H 1_{i, t-1}+\delta_{2} T E C H 2_{i, t-1}+\varepsilon_{i, t}$ If the SDI hypothesis is verified, then we could expect a technology shift from summation to best-shot around 1983. However, in statistical terms, this is one possibility amongst many others. With a time horizon of 21 years and 4 possible combinations of aggregation technologies, 84 models are in competition and must be investigated as such. Detailed estimations are provided in appendix 1. Only five models emerge with significant coefficients. Table 2 sums up the results. Model A 
evidences best-shot until 1972 and then summation. Model B does the same with a break in 1975. Model E begins with best-shot with a break in 1981 followed by another best-shot. Models C and D show two summation periods with respective breaks in 1980 and 1981.

(Table 2 about here)

We then run $\mathrm{J}$ tests in order to cross-evaluate the five models remaining in competition (detailed results are provided in appendix 2). Models A, B and E can be rejected at the $1 \%$ threshold. Models $\mathrm{C}$ and $\mathrm{D}$ are quite similar, with close break dates and the same aggregation pattern. None of them is rejected at the $1 \%$ threshold. Model D cannot be rejected at the 5\% threshold (except when compared to model C). At the $10 \%$ threshold, no specification dominates. All in all, model D and to a slightly lesser extent model $\mathrm{C}$ seem to provide the best specifications. A constant social composition function seems to prevail, namely summation, over the whole period comprehending the Strategic Defense Initiative. The econometric analysis does not confirm any technology shift towards best-shot.

Our result corroborates that of Conybeare et al. (1994) while using a different empirical strategy. Conybeare et al. (1994) distinguish best shot, weakest link, and summation aggregation technologies, and applied cross-sectional data analysis to four alliances on the entire period: Triple Alliance (1880-1914), Triple Entente (18801914), Warsaw Pact (1963-1987), and NATO (1961-1987). For the latter, the authors conclude on the prevalence of summation-type ally behavior over best-shot or weakest-link behavior (p.541). Here we use panel data and we allow a break in the considered period. Although the empirical strategies are different, both lines of research suggest that NATO abides by a summation aggregation technology as soon as conventional forces get more and more weight in the alliance. This is also the case 
with the Warsaw Pact (Conybeare et al. 1994). Best-shot attributes (nuclear deterrence by the alliance leaders) could provide incentives to free-ride on the best-shooter. However, potential risks of weakest-link would lead western allies voluntarily to engage into matching behaviors of sustained contributions to their alliance (matching would be centrally planned within the Warsaw Pact). Nonetheless, what we would like to discuss now is why a political initiative as striking and prominent as SDI did not trigger a shift in the social composition function of NATO.

\section{Discussion}

The expected shift of technology from summation to best-shot following SDI does not seem to take place. If ever there is a change in the behavior of the allies, it happens earlier in 1980 or 1981 and it remains within a summation framework with only a slight change in the contributing behavior of allies from the first to the second period. To try to understand why SDI does not shift the social composition function towards a best-shot aggregator, it may prove insightful to go back to the earlier years of NATO when the USA did play best-shot.

As Pedlow (1997) recalls it, the first prominent NATO strategy document emanates from the Military Committee (MC), composed of NATO's chiefs of staff. It is issued as directive MC3 on October 19, 1949. Reading MC3 is extremely rewarding for those interested in the making of collective action. The best-shot nature of the alliance at its inception is straightforwardly announced: "Insure the ability to deliver the atomic bomb promptly. This is primarily a US responsibility assisted as practicable by other nations" (MC3 7a). Under the item "cooperative measures", the directive claims that "The essence of our overall concept is to develop a maximum of strength through collective defense planning" (MC3 8). Though the expression 
"atomic bomb" is soon replaced in the later documents by "strategic bombing", it nevertheless remains that NATO basically aims at providing deterrence as a pure public good inside the alliance.

Deterrence is indeed plainly and forcefully described as such in directive MC48 of November 22, 1954. "In face of the threat of such a war, the primary aim of NATO, must more than ever before, be to prevent war. This aim can only be achieved if the Allied nations are so powerful in the vital elements of modern warfare that the enemy will conclude that he has little hope of winning a war involving NATO. This means that NATO must be able to withstand the initial Soviet onslaught, to deliver decisive atomic counter-attacks against the war-making capacity of the enemy, and to prevent the rapid overrunning of Europe" (MC48 33). In economic terms, deterrence is a pure public good. It is non rival: unlike situations involving conventional forces, retaliation can take place whatever the magnitude or geographical aim of the threat. It is also non-excludable: all allies are protected and none can be excluded. Finally, the use of the public good is mandatory once the allies have signed the Treaty. Deterrence is a credible commitment: the automatic pledge of retaliation is sustained by the fact that NATO would have a first-strike advantage and a second-strike capability thanks to its sufficient stockpile of nuclear weapons.

First-strike deterrence thus works as a collective good provided to the members of the alliance. The aggregation technology during 1949-1970 is not summation, but best-shot. This does not mean that non best-shot contributions are redundant or useless. The latter statement is largely denied by the very writing of such a fundamental document as directive MC48. Complementarity remains crucial in the alliance, thereby justifying the joint product approach. 
In a context of summation, SDI can appear as an attempt at reinstalling the best-shot status of the USA while securing the ballistic protection of the US territory. However, to become a successful best-shot implies that you have the capacity to provide the core of the public good that unites the allies. Now, SDI is a NMD policy with strategic aims that are radically different from standard Theater Missile Defense (TMD), like for instance Patriot missiles. Our point is that this national defense initiative amounts to fueling the alliance with a private good. SDI is indeed a public good at the US level but at the NATO level, it is a private good that becomes one of the joint products of the alliance as they have been analyzed by Sandler and Hartley (2001): strategic, tactical and conventional weapons are complementary in the overall strategy, and SDI is one of them. President Reagan's first mandate displays a political will to bend down the USSR, pushing forward a US national defense system in an alliance characterized from its inception by global nuclear deterrence.

Another aspect of our discussion is that the doctrine of flexible response initiated in the late 1960s shows a significant inflexion from 1981 until the shift to the crisis management doctrine in 1990 (Sandler and Murdoch 2000, Table 1, p.305). Besides the US efforts, France and UK proceed to build-up and modernize their strategic arsenals thereby increasing deterrence and the share of jointly produced nonexcludable public outputs. At the same time, NATO adopts the forward-defense (deep strike) strategy in 1984. Precision-guided munitions target the Warsaw Pact rearechelon forces. The new strategy reduces the importance of the thinning conventional forces. Sandler and Murdoch (2000) consider that this inflexion in the implementation of the flexible response doctrine augments the share of non-excludable benefits derived from defense. In the context of our discussion, if these events do increase the 
publicness of defense activity, this is not solely due to one ally but to the joined efforts of a handful of them, which decreases the likelihood of a single best-shot.

There are certainly lessons to be drawn from that "Star War" episode. It may illuminate the current debates on missile defense. Considering the current variety and dispersion of threats that NATO faces, the weakest-link technology may want renewed consideration, not only for moral hazard considerations but also for the possible technological weakness of the defense system of one of the allies. The achievement of the Territorial Missile Defense strategy might be a way to prevent it. The guess is that missile defense strategy, even within the framework of a summation social composition function, "would be able to knock down enough of an enemy's missiles so that if he ever pushed a button to attack, he would be doing so in the knowledge that his attack was unable to prevent a devastating retaliatory strike (Reagan's memoirs, quoted by Greenberg 2000, p.140). And the ballistic initiative of the USA would prove useful to NATO, if not best-shot. 
Table 1: Estimation results for the significant technology combinations without breakpoints

\begin{tabular}{ccc}
\hline Variables & $\begin{array}{c}\text { Model of } \\
\text { constant } \\
\text { summation }\end{array}$ & $\begin{array}{c}\text { Model of } \\
\text { constant } \\
\text { best-shot }\end{array}$ \\
\hline GDP & $\begin{array}{c}0.677^{* * *} \\
(0.081)\end{array}$ & $\begin{array}{c}0.683^{* * *} \\
(0.074)\end{array}$ \\
SUM & -0.025 & \\
& $(0.119)$ & \\
BS & & -0.036 \\
& & $(0.090)$ \\
\hline$R^{2}$ & 0.993 & 0.994
\end{tabular}

$(* * *)$ significant at the $1 \%$ level

Table 2: Estimation results for the significant technology combinations with breakpoints

\begin{tabular}{|c|c|c|c|c|c|}
\hline Variables & $\begin{array}{l}\text { Model A } \\
k=1972\end{array}$ & $\begin{array}{l}\text { Model B } \\
k=1975\end{array}$ & $\begin{array}{l}\text { Model C } \\
k=1980\end{array}$ & $\begin{array}{l}\text { Model D } \\
k=1981\end{array}$ & $\begin{array}{l}\text { Model E } \\
k=1981\end{array}$ \\
\hline$G D P$ & $\begin{array}{c}0.720 * * * \\
(8.913)\end{array}$ & $\begin{array}{c}0.714 * * * \\
(8.786)\end{array}$ & $\begin{array}{c}0.704 * * * \\
(9.859)\end{array}$ & $\begin{array}{c}0.713 * * * \\
(9.958)\end{array}$ & $\begin{array}{c}0.675 * * * \\
(9.900)\end{array}$ \\
\hline SUM1 & & & $\begin{array}{c}-0.217 * * \\
(-2.027)\end{array}$ & $\begin{array}{c}-0.243 * * \\
(-2.132)\end{array}$ & \\
\hline SUM2 & $\begin{array}{c}-0.010 * * \\
(-2.225)\end{array}$ & $\begin{array}{l}-0.009 * \\
(-1.927)\end{array}$ & $\begin{array}{c}-0.212 * * \\
(-1.996)\end{array}$ & $\begin{array}{c}-0.238 * * \\
(-2.106)\end{array}$ & \\
\hline$B S 1$ & $\begin{array}{l}-0.009 * \\
(-1.882)\end{array}$ & $\begin{array}{l}-0.008 * \\
(-1.763)\end{array}$ & & & $\begin{array}{l}-0.155^{*} \\
(-1.802)\end{array}$ \\
\hline$B S 2$ & & & & & $\begin{array}{l}-0.151 * \\
(-1.771)\end{array}$ \\
\hline$R^{2}$ & 0.994 & 0.994 & 0.995 & 0.995 & 0.995 \\
\hline
\end{tabular}

$(*),(* *),(* * *):$ respectively significant at $10 \%, 5 \%$ and $1 \%$ level 
Appendix 1: Estimations of breakpoints under the various aggregation combinations

\begin{tabular}{|c|c|c|c|c|c|c|c|}
\hline & pcse1970 & pcse1971 & pcse1972 & pcse1973 & pcse1974 & pcse 1975 & pcse 1976 \\
\hline$G D P$ & $0.701 * * *$ & $0.704 * * *$ & $0.748 * * *$ & $0.644 * * *$ & $0.652 * * *$ & $0.743 * * *$ & $0.693 * * *$ \\
\hline$S U M 1$ & -0.070 & -0.073 & -0.090 & -0.044 & -0.091 & -0.089 & -0.079 \\
\hline \multirow[t]{2}{*}{$S U M 2$} & -0.070 & -0.072 & -0.092 & -0.040 & -0.086 & -0.091 & -0.078 \\
\hline & pcse1977 & pcse1978 & pcse1979 & pcse1980 & pcse1981 & pcse1982 & pcse1983 \\
\hline$G D P$ & $0.706 * * *$ & $0.721 * * *$ & $0.706 * * *$ & $0.704 * * *$ & $0.713 * * *$ & $0.727 * * *$ & $0.711 * * *$ \\
\hline SUM1 & -0.099 & -0.093 & -0.146 & $-0.217 * *$ & $-0.243 * *$ & -0.139 & -0.092 \\
\hline \multirow[t]{2}{*}{ SUM2 } & -0.098 & -0.093 & -0.143 & $-0.212 * *$ & $-0.238 * *$ & -0.137 & -0.092 \\
\hline & pcse1984 & pcse1985 & pcse1986 & pcse1987 & pcse1988 & pcse1989 & pcse 1990 \\
\hline$G D P$ & $0.730 * * *$ & $0.744 * * *$ & $0.744 * * *$ & $0.766 * * *$ & $0.773 * * *$ & $0.741 * * *$ & $0.714 * * *$ \\
\hline SUM1 & -0.074 & -0.075 & -0.108 & -0.074 & -0.086 & -0.087 & -0.085 \\
\hline$S U M 2$ & -0.075 & -0.075 & -0.108 & -0.076 & -0.089 & -0.088 & 0.000 \\
\hline
\end{tabular}

\begin{tabular}{|c|c|c|c|c|c|c|c|}
\hline & pcse1970 & pcse1971 & pcse1972 & pcse1973 & pcse1974 & pcse1975 & pcse1976 \\
\hline$G D P$ & $0.662 * * *$ & $0.664 * * *$ & $0.715 * * *$ & $0.623 * * *$ & $0.619 * * *$ & $0.710 * * *$ & $0.660 * * *$ \\
\hline SUM1 & $0.012 * * *$ & 0.006 & $0.009 * *$ & 0.003 & 0.004 & $0.008 *$ & 0.001 \\
\hline \multirow[t]{2}{*}{$B S 2$} & $0.015 * * *$ & 0.008 & $0.008 *$ & $0.008 *$ & $0.010 * *$ & 0.007 & 0.002 \\
\hline & pcse1977 & pcse1978 & pcse1979 & pcse1980 & pcse1981 & pcse1982 & pcse1983 \\
\hline$G D P$ & $0.674 * * *$ & $0.688 * * *$ & $0.656^{* * * *}$ & $0.639 * * *$ & $0.644 * * *$ & $0.689 * * *$ & $0.700 * * *$ \\
\hline SUM1 & 0.002 & -0.000 & -0.005 & -0.005 & $-0.008 *$ & -0.003 & -0.001 \\
\hline \multirow[t]{2}{*}{$B S 2$} & 0.003 & -0.000 & -0.003 & -0.002 & -0.005 & -0.003 & -0.002 \\
\hline & pcse1984 & pcse1985 & pcse1986 & pcse1987 & pcse1988 & pcse1989 & pcse 1990 \\
\hline$G D P$ & $0.726 * * *$ & $0.738 * * *$ & $0.729 * * *$ & $0.749 * * *$ & $0.747 * * *$ & $0.711 * * *$ & $0.714 * * *$ \\
\hline SUM1 & -0.004 & -0.003 & 0.000 & 0.003 & 0.002 & 0.003 & -0.085 \\
\hline$B S 2$ & -0.006 & -0.005 & -0.000 & 0.000 & -0.001 & 0.003 & 0.000 \\
\hline
\end{tabular}




\begin{tabular}{|c|c|c|c|c|c|c|c|}
\hline & pcse1970 & pcse1971 & pcse1972 & pcse1973 & pcse1974 & pcse1975 & pcse 1976 \\
\hline$G D P$ & $0.674 * * *$ & $0.672 * * *$ & $0.720 * * *$ & $0.627 * * *$ & $0.624 * * *$ & $0.714 * * *$ & $0.662 * * *$ \\
\hline$B S 1$ & $-0.015^{* * *}$ & $-0.008 *$ & $-0.009 *$ & $-0.008 *$ & $-0.011 * *$ & $-0.008 *$ & -0.003 \\
\hline \multirow[t]{2}{*}{ SUM2 } & $-0.013 * * *$ & -0.007 & $-0.010^{* *}$ & -0.003 & -0.005 & $-0.009 *$ & -0.001 \\
\hline & pcse1977 & pcse1978 & pcse1979 & pcse1980 & pcse1981 & pcse1982 & pcse 1983 \\
\hline$G D P$ & $0.674 * * *$ & $0.687 * * *$ & $0.654 * * *$ & $0.637 * * *$ & $0.642 * * *$ & $0.688 * * *$ & $0.700 * * *$ \\
\hline$B S 1$ & -0.004 & -0.001 & 0.002 & 0.001 & 0.004 & 0.002 & 0.001 \\
\hline \multirow[t]{2}{*}{$S U M 2$} & -0.003 & -0.001 & 0.004 & 0.004 & 0.006 & 0.002 & 0.001 \\
\hline & pcse1984 & pcse1985 & pcse1986 & pcse1987 & pcse1988 & pcse1989 & pcse1990 \\
\hline$G D P$ & $0.726^{* * * *}$ & $0.739 * * *$ & $0.731 * * *$ & $0.750 * * *$ & $0.747 * * *$ & $0.712 * * *$ & $0.704 * * *$ \\
\hline$B S 1$ & 0.005 & 0.004 & -0.001 & -0.001 & -0.000 & -0.004 & -0.064 \\
\hline SUM2 & 0.003 & 0.003 & -0.001 & -0.003 & -0.003 & -0.004 & 0.000 \\
\hline
\end{tabular}

\begin{tabular}{cccccccc}
\hline & $\mathrm{p} c s e 1970$ & $\mathrm{pcse} 1971$ & $\mathrm{pcse} 1972$ & $\mathrm{pcse} 1973$ & $\mathrm{pcse} 1974$ & $\mathrm{pcse} 1975$ & $\mathrm{pcse} 1976$ \\
\hline$G D P$ & $0.678 * * *$ & $0.685 * * *$ & $0.729 * * *$ & $0.630 * * *$ & $0.631 * * *$ & $0.725 * * *$ & $0.681 * * *$ \\
$B S 1$ & -0.036 & -0.041 & -0.073 & -0.013 & -0.043 & -0.070 & -0.056 \\
$B S 2$ & -0.034 & -0.040 & -0.074 & -0.009 & -0.037 & -0.071 & -0.054 \\
\hline & $\mathrm{pcse} 1977$ & $\mathrm{pcse} 1978$ & $\mathrm{pcse} 1979$ & $\mathrm{pcse} 1980$ & $\mathrm{pcse} 1981$ & $\mathrm{pcse} 1982$ & $\mathrm{pcse} 1983$ \\
\hline$G D P$ & $0.689 * * *$ & $0.707 * * *$ & $0.684 * * *$ & $0.671 * * *$ & $0.675 * * *$ & $0.703 * * *$ & $0.702 * * *$ \\
$B S 1$ & -0.074 & -0.067 & -0.092 & $-0.133 *$ & $-0.155 *$ & -0.085 & -0.068 \\
$B S 2$ & -0.073 & -0.067 & -0.090 & -0.129 & $-0.151 *$ & -0.084 & -0.068 \\
\hline$G D P$ & $0.735 * * *$ & $0.746 * * *$ & $0.733 * * *$ & $0.755 * * *$ & $0.759 * * *$ & $0.727 * * *$ & $0.704 * * *$ \\
$B S 1$ & -0.049 & -0.046 & -0.083 & -0.055 & -0.061 & -0.066 & -0.064 \\
$B S 2$ & -0.050 & -0.048 & -0.082 & -0.057 & -0.064 & -0.066 & 0.000 \\
\hline
\end{tabular}

$(*),(* *),(* * *)$ : respectively significant at $10 \%, 5 \%$ and $1 \%$ level 
Appendix 2: J tests

\begin{tabular}{cccccc}
\hline & A versus A & A versus B & A versus C & A versus D & A versus E \\
\hline GDP & 0.0000 & 0.1408 & 0.0555 & 0.0596 & 0.0231 \\
$B S 1$ & 0.0000 & -0.0072 & $-0.0078^{*}$ & $-0.0077^{*}$ & $-0.0087^{*}$ \\
BS2 & & & & \\
SUM1 & & & & \\
SUM2 & 0.0000 & $-0.0085^{*}$ & $-0.0091^{* *}$ & $-0.0089^{* *}$ & $-0.0102^{* *}$ \\
\hline & & & & & \\
\hline & & & & & \\
J-test estimates (a) & $1.0000^{* * *}$ & 0.8396 & $0.9699^{* * *}$ & $0.9643 * * *$ & $1.0250^{* *}$ \\
\hline
\end{tabular}

\begin{tabular}{cccccc}
\hline & B versus A & B versus B & B versus C & B versus D & B versus E \\
\hline GDP & 0.0986 & 0.0000 & 0.0386 & 0.0467 & 0.0142 \\
$B S 1$ & -0.0062 & 0.0000 & -0.0060 & -0.0058 & -0.0067 \\
BS2 & & & & \\
SUM1 & & & & -0.0066 & $-0.0079^{*}$ \\
SUM2 & -0.0068 & 0.0000 & $-0.0069^{*}$ & & \\
\hline & & & & & \\
\hline
\end{tabular}

\begin{tabular}{cccccc}
\hline & C versus A & C versus B & C versus C & C versus D & C versus E \\
\hline GDP & 0.0535 & 0.0897 & -0.0000 & 0.0495 & 0.1172 \\
$B S 1$ & & & & \\
BS2 & & & & \\
SUM1 & $-0.1984^{*}$ & $-0.1949 *$ & -0.0000 & -0.1141 & -0.1377 \\
SUM2 & $-0.1937^{*}$ & $-0.1901^{*}$ & -0.0000 & -0.1098 & -0.1335 \\
\hline & & & & & \\
\hline & & & & & \\
\hline
\end{tabular}




\begin{tabular}{cccccc}
\hline & D versus A & D versus B & D versus C & D versus D & D versus E \\
\hline GDP & 0.0821 & 0.1411 & 0.0443 & 0.0000 & $1.5766^{*}$ \\
$B S 1$ & & & & \\
BS2 & & & & \\
SUM1 & $-0.2216^{*}$ & $-0.2197^{*}$ & -0.1321 & -0.0000 & $-0.4869^{* *}$ \\
$S U M 2$ & $-0.2169^{*}$ & $-0.2149^{*}$ & -0.1278 & -0.0000 & $-0.4771^{* *}$ \\
\hline & & & & & \\
\hline & & & & & \\
J-test estimates & $0.9112^{*}$ & 0.8174 & $0.8876^{* *}$ & $1.0000^{* * *}$ & -1.2180 \\
\hline
\end{tabular}

\begin{tabular}{cccccc}
\hline & E versus A & E versus B & E versus C & E versus D & E versus E \\
\hline GDP & -0.0477 & -0.0020 & 0.0143 & -0.6706 & 0.0000 \\
$B S 1$ & $-0.1639^{*}$ & $-0.1544^{*}$ & -0.0695 & 0.1817 & 0.0000 \\
$B S 2$ & $-0.1597^{*}$ & $-0.1502^{*}$ & -0.0659 & 0.1763 & 0.0000 \\
SUM1 & & & & \\
SUM2 & & & & \\
\hline & & & & \\
J-test estimates & $1.0585^{* *}$ & $0.9761^{*}$ & $0.9171^{* * *}$ & $2.0025^{* *}$ & $1.0000^{* *}$ \\
\hline
\end{tabular}

(a) If the coefficient is statistically significant, the competing model specification is the best

$(*),(* *),(* * *)$ : respectively significant at $10 \%, 5 \%$ and $1 \%$ level 


\section{References}

Beck, N., Katz, J. (1995) What to do (and not to do) with time series cross-section data. American Political Science Review 89 (3), 634 - 647.

Brams, S., Kilgour, M. (1988) Deterrence versus defense: A game-theoretic model of Star Wars. International Studies Quarterly 32 (1), 3 - 28.

Conybeare, J., Murdoch, J., Sandler, T. (1994) Alternative collective-goods models of military alliances: Theory and empirics. Economic Inquiry 32 (4), 525 - 542.

Cornes, R. (1993) Dyke maintenance and other stories: Some neglected types of public goods. The Quarterly Journal of Economics 108 (1), 259 - 271.

Cornes, R., Hartley, K. (2007) Weak links, good shots and other public goods games: building on BBV. Journal of Public Economics 91 (9), 1684 - 1707.

Dutheil de la Rochère, G. Josselin, J-M., Rocaboy, Y. (2011) The role of aggregation technologies in the provision of supranational public goods: A reconsideration of NATO's strategies. Review of International Organizations 6 (1), 85 - 103.

Freedman, L. (2003) The evolution of nuclear strategy. Palgrave MacMillan.

Gadea, M., Pardos, E., Perez-Fornies, C. (2004) A long-run analysis of defence spending in the NATO countries (1960-99). Defence and Peace Economics 15 (3), $231-249$

Greenberg, D. (2000) The Empire strikes out. Why Star Wars did not end the Cold War. Foreign Affairs 79 (2), 136 - 142.

Hirshleifer, J. (1983) From weakest-link to best-shot: The voluntary provision of public goods. Public Choice 41 (3), 371 - 386.

Khanna, J., Sandler, T. (1996) NATO burden sharing: 1960-1992. Defence and Peace Economics 7 (2), 115 - 133. 
O’Hanlon, M. (1999) Star War strikes back. Foreign Affairs 78 (6), 68 - 82.

O’Neal, J., Elrod, M. (1989) NATO burden sharing and the forces of change. International Studies Quarterly 33 (4), 435 - 456.

Pedlow, G. (1997) NATO strategy documents 1949-1969. NATO archives.

Samuelson, P. (1954) The pure theory of public expenditure. Review of Economics and Statistics 36 (4), 387 - 389.

Sandler, T. (1977) Impurity of defense: An application to the economics of alliances. Kyklos 30 (3), 433 - 460.

Sandler, T. (2006) Hirshleifer's social composition function in defense economics. Defense and Peace Economics 17 (6), 645 - 655.

Sandler, T., Forbes, J. (1980). Burden sharing, strategy, and the design of NATO. Economic Inquiry 18: (3), 425 - 444.

Sandler, T., Hartley, K. (2001) Economics of alliances: The lessons for collective action. Journal of Economic Literature 39 (3), 869 - 896.

Sandler, T., Murdoch, J. (2000) On sharing defence burdens in the 1990s and beyond. Fiscal Studies 21 (3), 297 - 327.

Zervos, V. (2004) The impact of the US Strategic Defense Initiative on the space race. Defense and Peace Economics 15 (4), 365 - 377. 